\title{
Heat Transfer and Energy Loss in Bitumen Batching System of Asphalt Mixing Plant
}

\author{
Justas Bražiūnas, Henrikas Sivilevičius \\ Vilnius Gediminas Technical University, Department of Transport Technological Equipment, Plytinès st. 27, LT-10105 Vilnius, Lithuania
}

\begin{abstract}
Bitumen should always be stored and handled at the lowest temperature possible, consistent with efficient use. At higher temperatures and lower viscosities pumping is optimized; whereas at lower temperatures and higher viscosities pumping efficiency decreases rapidly. Thus viscosity and its control by temperature is an important consideration in respect to all handling operations. The minimization of bituminous hardening during storing, transportation and mixing depends on careful control of binder temperature. TRA ASFALTAS 08 regulates maximum permitted storage temperatures of various bitumens. Heating equipment of periodical asphalt mixing plant (AMP) bitumen batching system (BBS) shall be designed to maintain the same temperature of the binder in the whole BBS. This article presents the study of heat transfer in bitumen storage tanks and identifies the most important factors influencing on energy loss. The test showed that energy loss in currently operated AMP is too high and may be reduced by changing technological parameters of bitumen heating, updating and upgrading separate heating equipment and improving temperature control and handling of heating equipment. The method of convection and radiation heat flow calculation in bitumen storage tank is presented. The findings obtained through the use of the described method of heat flow calculation correspond to the actual data of the consumed electrical power displayed on AMP computer.
\end{abstract}

Keywords: bitumen; temperature; Asphalt Mixing Plant (AMP); Bitumen Batching System (BBS); heat transfer; convection; radiation; viscosity; heat loss; energy loss.

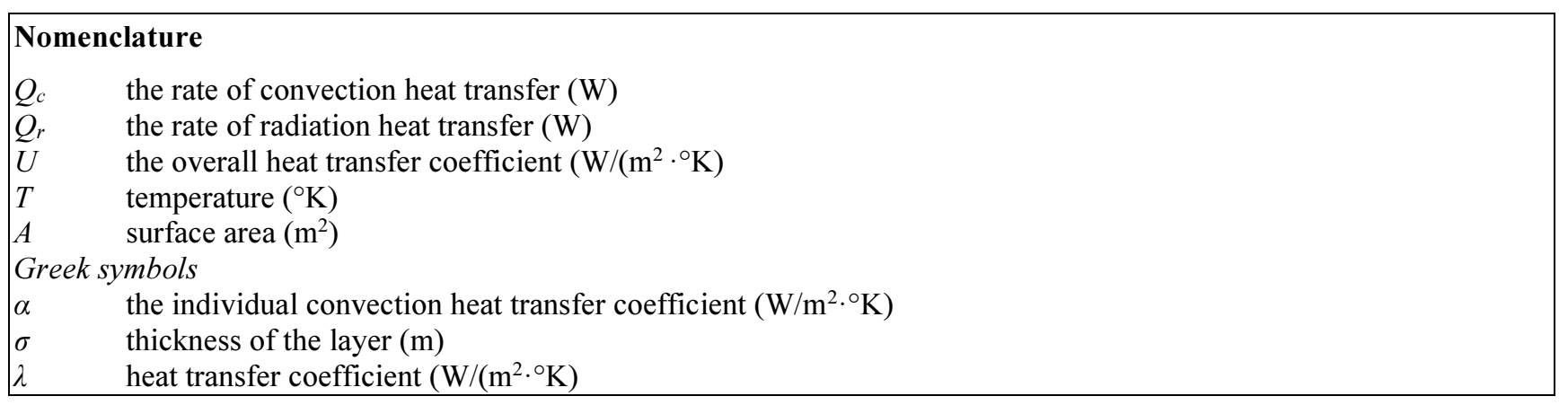

\section{Introduction}

One of most important bitumen batching system (BBS) technological parameters is temperature, which influences the physical, chemical, rheological and mechanical properties of the produced asphalt mixture. Bitumen may be rigid and friable at low temperature, liquid and fluid at high temperature and semi-rigid or rigid at medium temperature. Bitumen dynamic modulus due to temperature fluctuations from $-30^{\circ} \mathrm{C}$ to $50^{\circ} \mathrm{C}$ change even 37000 times [1]! When asphalt mixture is produced of too cool and, therefore, too viscous (consistent) bitumen, it hardly turns into a thin film, which should coat all mineral particles with solid layers of appropriate thickness and make a strong compacted structure of the mixture. When too hot or overheated mineral aggregates are used, bitumen may burn: it degrades chemically, volatilizes, its colloidal composition changes and rheological properties deteriorate.

Corresponding author: Justas Bražiūnas. E-mail address: justas.braziunas@vgtu.lt

http://dx.doi.org/10.3846/enviro.2014.146

(C) 2014 The Authors. Published by VGTU Press. This is an open-access article distributed under the terms of the Creative Commons Attribution License, which permits unrestricted use, distribution, and reproduction in any medium, provided the original author and source are credited. 
One of the most important engineering peculiarities of bitumen is that its main properties depend on temperature a lot. The chemical composition [2] of bitumen is extremely complex. When conducting experimental investigations it is separated into two main fractions: asphaltenes and maltenes. Maltenes are separated into saturates, aromatics and resins. Four fractional groups are not clearly defined and overlap; however, rheological properties of bitumen may be determined and controlled according to the interrelation of these groups by its chemical composition. Each of the four bitumen chemical fractions has different temperature susceptibility. The formation of all these chemical fractions correlate differently depending on the changing temperature of the binder. The presence of aromatics and asphaltenes may reduce temperature susceptibility, and saturates and resins may have a negative impact on temperature susceptibility [3].

The most important bitumen ageing mechanisms are as follows: oxidation, volatilisation, steric or physical factors and exudative hardening. Ageing due to oxidation is the key factor if compared with other factors impacting on ageing [4], [5]. Oxidation rate mostly depends on temperature [6], duration and intensity of interaction with oxygen as well as the thickness of bitumen film, which coats aggregate particles [7]. Heating duration and temperature have a significant impact on such rheological properties of bitumen as viscosity [8] or complex modulus. Scientists from various countries [9-11] have investigated and compared forecasting models of the impact of bitumen's critically high temperature on the properties of hot mix asphalt (HMA) mixture.

HMA mixture production requires huge energy resources. Investigations have proved that energy is frequently used ineffectively in the production of HMA [12]. Bitumen in all BBS of asphalt mixing plant (AMP) is stored at the temperature of ca $160{ }^{\circ} \mathrm{C}$, and its temperature shall be the same in the whole system. Bitumen properties are destroyed through overheating; it undergoes oxidation, i. e. rapid bitumen grade change occurs [13], [14] and harmful vaporisation intensifies [15-17]. At low temperature, bitumen viscosity increases and it becomes more difficult to be pumped. The production of warm mix asphalt (WMA) mixtures takes place at lower temperature; therefore, its production technology is one of the most important factors influencing on the demand of energy [18].

HMA mixture is produced in AMP of various types and capabilities, different structure, productivity, various technological schemes, the most popular of which are batch-type mixing plants [19], [20]. Energy consumption is a very important parameter when purchasing a new AMP, which impacts on the cost price of HMA mixture and plant's competitiveness [21]. Taking into account all technological processes, energy consumption of batch-type AMP is higher than that of drum-type AMP. It is basically due to the fact that in a drum-type AMP mineral materials are dried, heated and mixed in the same drum. Inspite of that, currently batch-type AMP are more popular due to their versatility, handling and better quality of production [22]. Moreover, penetration of bitumen binder after the production process in a batch-type AMP decreases by $14 \%$ less than after the production in a drum-type AMP [23].

Physical properties of bitumen binder depend on the temperature a lot [24]. Viscosity is a fundamental property, which describes the resistance of liquid to deformations or flow, based on the internal friction of the molecules of that liquid. When an asphalt mixture is produced and pavement is compacted, bitumen shall be of optimal viscosity. If bitumen viscosity is too high when mixing asphalt mixture, aggregates will not be coated with the binder properly, and if its viscosity is too low, bitumen will coat particles, but may drain when stored or transported. For satisfactory coating of aggregates, bitumen viscosity shall be ca $0.2 \mathrm{~Pa} \cdot \mathrm{s}$. Dynamic viscosity may have impact on HMA mixture dynamic modulus $E$ : when viscosity increases, modulus increases too [25]. It has been proved that dynamic modulus $E$ may be used as a criterion of road asphalt pavement resistance to rutting [26].

Dynamic viscosity is a key factor to be taken into account when pumping, transporting and storing bitumen. Viscosity depends on the temperature, type and mark of the binder. Fig. 1 shows temperature-viscosity ratios of four marks of road bitumen and two marks of oxidized bitumen. There are also three lines defining the temperatures at which pumping, mixing and spraying possibilities are preserved [27], [28].

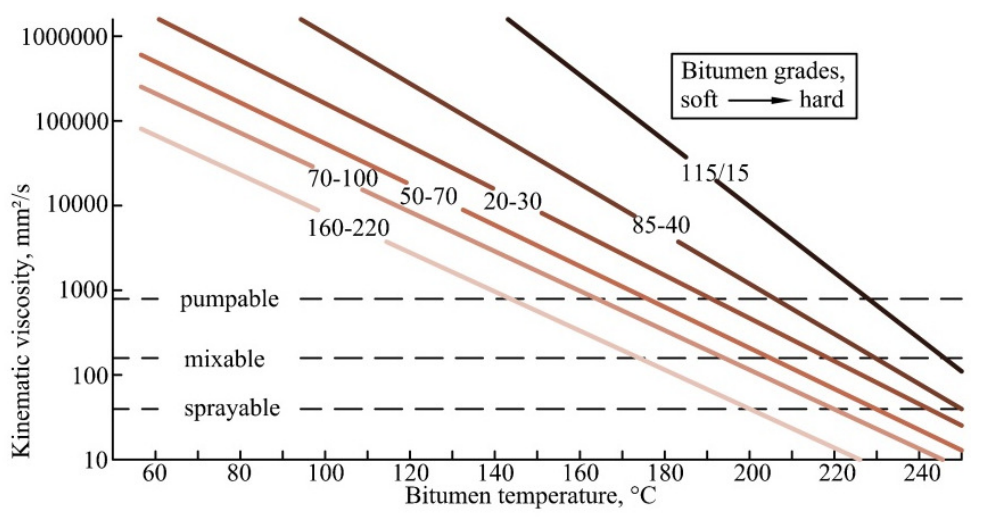

Fig. 1. Kinematic viscosity as a function of temperature for paving grade bitumen. Design pumpability, mixability and sprayability [27]

To pump bitumen, higher temperature and lower viscosity are optimal; however, when viscosity is higher and temperature is lower, the efficiency of pumping decreases very rapidly. Due to these reasons, when changing temperature, the control of viscosity is an essential condition in performing all bitumen transporting operations. The selection of optimal 
temperature is important not only due to technological, but to economic reasons as well. The higher the temperature, the more energy is consumed for heating bitumen, which increases the price cost of HMA mixture.

The aim of the paper is to investigate heat transfer occurring in bitumen tanks of AMP and to determine the key factors influencing on thermal losses and increase power consumption. It also aims to evaluate how the electrical power consumption for heating bitumen changes at different ambient temperature and the speed of the wind.

\section{Heat transfer in BBS equipment}

BBS of AMP is transport technological equipment for intaking, storing, heating, transporting and batching (weighing and measuring) of a set mass (capacity) bitumen binder batches when producing HMA mixture. BBS consisting of tanks, heating equipment, pumps, pipeline and a batcher is considered a complicated pipeline transport, which should not only transport liquid bitumen binder from one place to another, but batch it accurately and protect from possible damage.

BBS consists of four main groups of technological equipment: tanks, technological pipeline, a batcher and BBS heating equipment. Energy losses are incurred throughout all BBS. To heat bitumen in tanks, most of the energy consumed for heating is used. Bitumen of various marks is stored in tanks, the temperature of which most frequently varies from $130{ }^{\circ} \mathrm{C}$ to $180^{\circ} \mathrm{C}$, depending on its mark. Each AMP contains 3-7 independent insulated tanks fitted with heating equipment. It also contains a pipeline fitted with its individual heating elements, which connects the tanks with each other and a bitumen pump to pump bitumen from a tanker to tanks. The manufacturers of different AMP offer both vertical and horizontal tanks most often of the capacity of $60-120 \mathrm{~m}^{3}$. To produce various HMA mixtures, bitumen of various marks is used, the physical properties of which differ; therefore, several tanks connected into one common system are usually mounted on each AMP. The Lithuanian Inventory of Road Asphalt Mixture Specifications TRA ASFALTAS 08 [29] states the regulations on various types of road and polymer-modified bitumen, which shall be complied with when selecting bitumen heating modes (Table 1) [30], [31].

Table 1. Maximum permitted temperature of bitumen in a storage tank [31]

\begin{tabular}{lll}
\hline Bitumen & Type of bitumen & Maximum temperature ${ }^{\circ} \mathrm{C}$ \\
\hline Road bitumen & $20 / 30$ & 200 \\
\cline { 2 - 3 } & $35 / 50$ & 190 \\
\cline { 2 - 3 } $50 / 70$ & 180 \\
\cline { 2 - 3 } $70 / 100$ & 180 \\
\cline { 2 - 3 } & $100 / 150$ & 170 \\
\cline { 2 - 3 } & $160 / 220$ & 170 \\
\hline PMB bitumen & PMB 40/100-65 E & 190 \\
\cline { 2 - 3 } & PMB 25/55-60 & 180 \\
\cline { 2 - 2 } & PMB 45/80-55 & 180 \\
\cline { 2 - 2 } & PMB 65/105-50 & 180 \\
\hline
\end{tabular}

Technological pipeline transport in an AMP is used to transport bitumen binder from a tanker to a tank, from one tank to another and from a tank to a batcher. The peculiarity of this pipeline is that it has to comply with the technological requirements when transporting the liquid: it shall be transported at such speed (debit), which guarantees the maximum AMP job-mix formula efficiency. When transported, the same temperature of bitumen shall be maintained to ensure uniform viscosity and high quality mixing (the mixture was heterogeneous). US standard ASTM D2493 / D2493M [32] presents the graph of bitumen temperature and viscosity dependences, which shows how the dynamic viscosity of the mixture changes depending on its temperature (Table 2). When the temperature of bitumen falls from $160{ }^{\circ} \mathrm{C}$ to $140{ }^{\circ} \mathrm{C}$, its dynamic viscosity increases 3 times, and when it falls to $100{ }^{\circ} \mathrm{C}$, it increases by $60-70$ times! Maximum permitted bitumen storage temperatures are laid down in the Lithuanian Specifications TRA ASFALTAS [29].

Table 2. Dynamic viscosity of bitumen of varying temperatures [32]

\begin{tabular}{cc}
\hline Temperature $t,{ }^{\circ} \mathrm{C}$ & Dynamic viscosity $\eta, \mathrm{Pa} \cdot \mathrm{s}$ \\
\hline 180 & 0.07 \\
\hline 160 & 0.1 \\
\hline 140 & 0.3 \\
\hline 120 & $0.8-0.9$ \\
\hline 100 & $6-7$ \\
\hline 80 & 25 \\
\hline
\end{tabular}

BBS pipeline is insulated and heated at its full length. Heating cables, which are divided into separate segments, are switched on when heating sensors send a signal about the dropped temperature below the set level (frequently when HMA mixture production does not takes place) in a pipeline. To transport the bitumen, gear bitumen pumps driven by three-phase engines of various productivity are used. Pumps are fitted with independent heating elements. BBS heating equipment and thermal insulation in tanks, pipeline and a batcher, shall ensure uniform temperature of the hot binder in the whole system and minimum power consumption. 
The temperature maintained in bitumen storage tanks of oil refinery plants, tankers transporting bitumen or railway cisterns is $140-160{ }^{\circ} \mathrm{C}$, but not lower than minimum pumping temperature of ca $120{ }^{\circ} \mathrm{C}$ (for different marks it varies a little bit). Heating equipment is usually installed on the floor of the tank of vehicles, which enables to maintain the workable temperature of bitumen during transportation. It is aimed to deliver bitumen of workable temperature as its heating from the temperature lower than $140{ }^{\circ} \mathrm{C}$ may take almost a week depending on the quantity of the heated bitumen. Losses are also incurred due to additional energy consumption and the time is wasted. The number of heating and cooling cycles also has an impact on the change of hot binder properties. When crude oil is refined and transported and during technological stages of HMA mixture production, bitumen is rarely cooled to the ambient temperature. Moreover, it frequently occurs only in an oil refinery plant or AMP in winter or at the end of the road construction works season. It takes a lot of time, and up to 4,500 $\mathrm{kWh}$ of electrical power may be consumed in 24 hours to heat some $60 \mathrm{~m}^{3}$ capacity bitumen tanks filled only by 50 per cent. The rate of short-term ageing in tanks depends on the number of heating and cooling cycles of bitumen stored in AMP tanks. The rate of ageing due to volatile fraction vaporisation and change of the binder grade near the heating elements depends on the time of storage of bitumen in the tank. Storage and preparation for use of bitumen necessary for HMA mixture production is an energy-consuming and expensive process. Bitumen of various marks is usually stored at the temperatures of $150-170{ }^{\circ} \mathrm{C}$; therefore, to maintain the set temperature, powerful $9-46 \mathrm{~kW}$ capacity heating elements shall be installed in the tanks. The most important factors influencing on the rate of heat flow in a bitumen tank is bitumen content and temperature in a tank; however, the flow is impacted by other factors as well (Fig. 2).

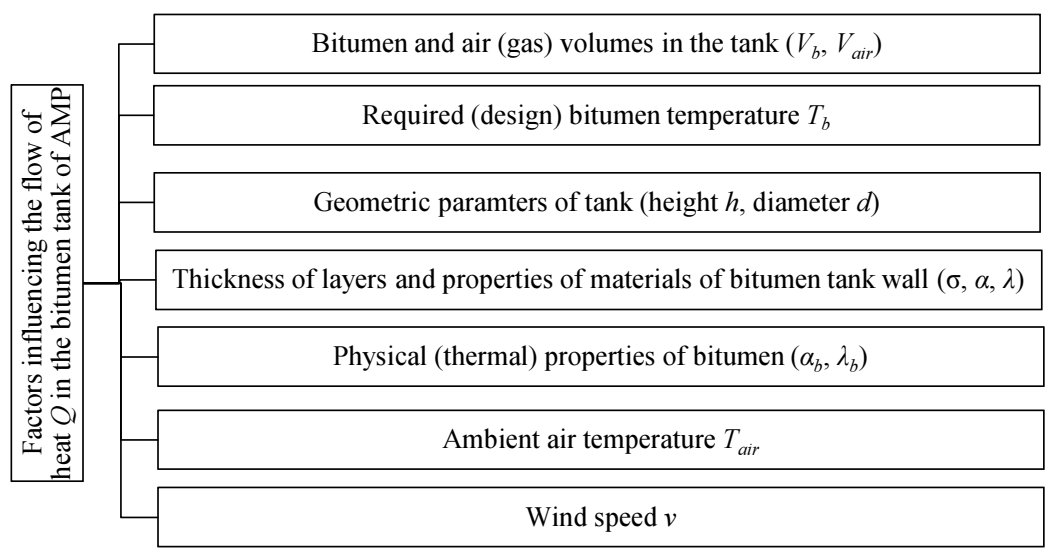

Fig. 2. Factors influencing the flow of heat $Q$ in the bitumen tank of AMP

In a bitumen tank heat may be transferred in three ways: through conduction, convection and radiation. In convection, heat is transferred by liquid or gas. In case of BBS, bitumen in tanks transfers heat via the wall of the tank by air molecules outside the tank. Convection heat transfer is always related to the conduction heat transfer all liquids and gases are more or less conductive to heat. The rate of convection heat transfer is calculated as follows:

$$
Q_{c}=A U\left(T_{b}-T_{a i r}\right),
$$

here $Q_{c}$ - convective heat transfer, $\mathrm{W} ; U$ - the overall heat transfer coefficient $\mathrm{W} /\left(\mathrm{m}^{2} \cdot{ }^{\circ} \mathrm{K}\right) ; T_{b}-$ bitumen temperature, ${ }^{\circ} \mathrm{K}$; $T_{\text {air }}$ - ambient air temperature, ${ }^{\circ} \mathrm{K}$.

Thermal radiation propagates through the vacuum of space. The heat of the hotter part of the body turns into radiation energy and propagates by electromagnetic waves in all directions. When it is transferred to another body, it may sink and become heating energy. In the case of the bitumen tank under investigation (Fig. 3a, b), bitumen of average temperature $T_{b}$ and heat transfer coefficient $\alpha_{l}$ washes from one side through a multi-layered wall, the thickness of which are $\sigma_{l}, \sigma_{i z o l}, \sigma_{3}$, heat conductivity coefficients $\lambda_{1}, \lambda_{i z o l} ., \lambda_{3}$ and surface area $A$; whereas on the other side it is exposed to air at $T_{\text {air }}$ and $\alpha_{2} . T_{b}>$ $T_{\text {air }}$. The temperatures of wall surfaces are not known, but it is clear that $T_{s 1}>T_{s 2}>T_{s 3}>T_{s 4}$, as $T_{b}>T_{\text {air }}$ (Fig. 3c). Suppose the process of heat transfer is stationary, then heat transfer coefficient $U$ is equal to:

$$
U=\frac{1}{\frac{1}{\alpha_{1}}+\frac{\sigma_{1}}{\lambda_{1}}+\frac{\sigma_{\text {insul }}}{\lambda_{\text {insul }}}+\frac{\sigma_{3}}{\lambda_{3}}+\frac{1}{\alpha_{2}}},
$$

here $\alpha_{l}-$ the individual convection heat transfer coefficient for bitumen, $\mathrm{W} / \mathrm{m}^{2}{ }^{\circ} \mathrm{K} ; \sigma_{l}-$ steel wall thickness, m; $\lambda_{1}-$ the thermal conductivity of the steel, $\mathrm{W} / \mathrm{m} \cdot{ }^{\circ} \mathrm{K} ; \sigma_{\text {insul }}$ - insulation thickness, $\mathrm{m} ; \lambda_{\text {insul }}$ - the thermal conductivity of the insulation, $\mathrm{W} / \mathrm{m} \cdot{ }^{\circ} \mathrm{K} ; \sigma_{3}$ - tin sheet thickness, $\mathrm{m} ; \lambda_{3}-$ the thermal conductivity of the tin sheet, $\mathrm{W} / \mathrm{m} \cdot{ }^{\circ} \mathrm{K} ; \alpha_{2}-$ the individual convection heat transfer coefficient for ambient air, $\mathrm{W} / \mathrm{m}^{2} \cdot{ }^{\circ} \mathrm{K}$. 
a)

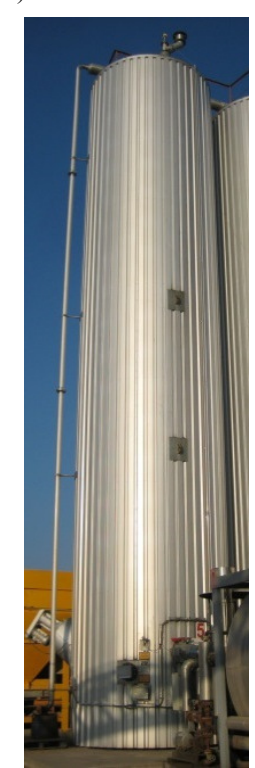

b)

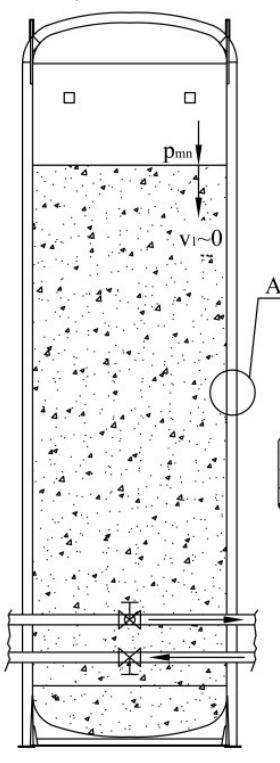

c)

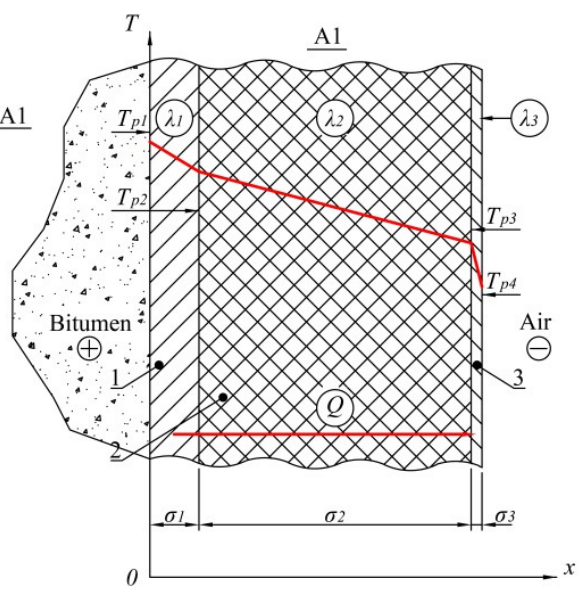

Fig. 3. Bitumen tank: a - image of tank; b-scheme of tank; $\mathrm{c}-$ scheme of wall layers of bitumen tank ( $1-$ layer of steel wall; $2-$ layer of insulation; 3 - layer of decorative tin sheet to protect against external influences)

It is possible to transfer heat by radiation from one place to another in two cases: when the surfaces of the bodies are parallel and when one body surrounds the other. In the first case and in the case under investigation the heat flow is calculated according to Stefan-Boltzmann law:

$$
Q_{r}=\varepsilon_{s} C_{0} A_{1}\left[\left(\frac{T_{1}}{100}\right)^{4}-\right]\left(\frac{T_{2}}{100}\right)^{4}
$$

here $Q_{r}$ - heat flux, $\mathrm{W} ; T_{1}, T_{2}$ - body surface temperature, ${ }^{\circ} \mathrm{K} ; \varepsilon_{s}$ - emissivity is the ratio of a surface's ability to emit radiant energy compared with the ability of a perfect black body of the same area at the same temperature.; $C_{0}-$ Stefan-Boltzmann constant $\left(5.67 \mathrm{~W} \mathrm{~m}^{-2}{ }^{\circ} \mathrm{K}^{-4}\right)$. The total heat flux due to convection and radiation is calculated:

$$
Q=Q_{c}+Q_{r} .
$$

When the general heat flow is determined, the amount of energy necessary to restore the workable bitumen temperature may be calculated due to radiation and convection.

\section{Investigation of Power Losses in BBS}

AMP tanks, a batcher, pumps, valves and other BBS elements are fitted with independent heating equipment. A tank is heated by electricity or gas. Most of the heat is transferred to bitumen via the base heating element, which is protuberant ca $1 \mathrm{~m}$ above the tank's floor. Its power ranges from 23 to $46 \mathrm{~kW}$. Additional heating takes place via additional heating equipment at the very bottom of tanks, which generate the power of $12 \mathrm{~kW}$. Additional heating equipment consists of a cable laid on the whole bottom area (up to $20 \mathrm{~m}$ ) or heating bars. Different manufacturers of tanks manufacture heat tanks of different materials and insulating materials of various thickness. There is no data showing that the insulating layer is selected according to the exploitation place of AMP. Therefore, in the future it will be important to investigate if AMP manufacturers justly do not offer different tanks of different insulating parameters (i.e. taking into account a region, climate, applied HMA mixture production technologies).

To maintain the same temperature in a pipeline when bitumen is not produced, all BBS pipeline is heated as well. Moreover, the whole pipeline is insulated: $1 \mathrm{~m}$ of a pipe is wrapped with ca $2 \mathrm{~m}$ of heating cable, the power of which is 60 $\mathrm{W} / 1 \mathrm{~m}$. Bitumen pumps are heated by contact heating elements. To heat a batcher, heated oil or a heating cable is used. The biggest problems related to BBS heating equipment are as follows:

- Some types of BBS equipment are not properly insulated. Heat energy freely radiates to ambient air;

- at critical BBS points bitumen congestion occurs due to cooled elements of the system;

- Heating of a pipeline by cable is ineffective due to irrationally divided outline of the cable (cable heating is turned on when a heating sensor transfers a signal about the dropped temperature to the handling computer. If the outline is long, the number of sensors mounted on it is too small (or there is only one) and bitumen cools differently at different spots. Heating is not turned on independently from bitumen congestion occurring at poorly insulated points);

- It may take up to a few days to reheat the hardened bitumen in a pipeline. 
The study shows that heat losses in BBS depend on the temperatures of bitumen and ambient air, wind speed, ratio of bitumen and air in a tank (bitumen content in a tank), thickness of the tank's wall layers, insulation properties and the quality of mounting. When studying the bitumen tanks of one AMP 6 operating in Lithuania, the electrical power consumption of the base and additional heating equipment of the tank in 24 hours was investigated (Fig. 4a).
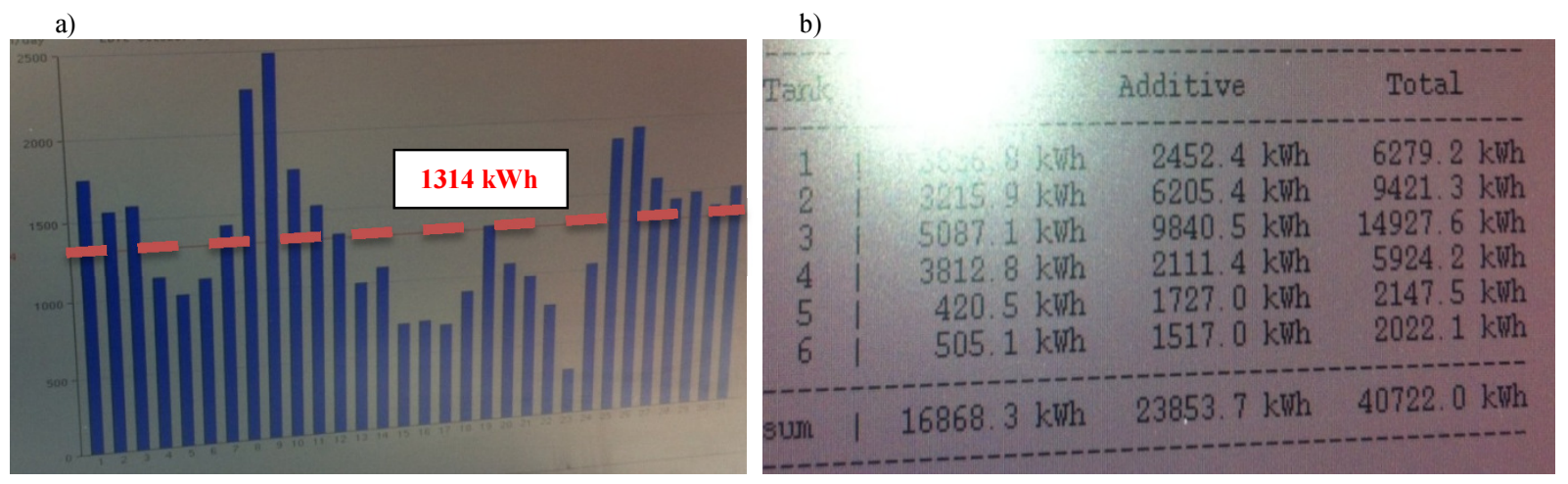

Fig. 4. Data on: a - electrical power consumption in a $120 \mathrm{~m}^{3}$ bitumen tank in October (the dotted line marks an average quantity of the power consumed in 24 hours; 2 - the electrical power consumption in six bitumen storage tanks by base and additional heating equipment in October

The total average electrical power consumed by the heating equipment of all six tanks, the maximum capacity of which is $246 \mathrm{~kW}$, was analysed. Having calculated the arithmetic mean of all days of the month, it was identified that on average electrical power consumption in 24 hours is $1.314 \mathrm{kWh}$.

Taking into account the dynamics of the power consumed by one tank, an assumption was made that geometrical and insulating parameters of a tank have no impact on the power consumption. Having analysed the dynamics of power consumption in a month, it was identified that most of the power is consumed when the temperature of bitumen in a tank has to be increased. For example, on 8 October when 65 tonnes of bitumen had to be heated from $145{ }^{\circ} \mathrm{C}$ to $150{ }^{\circ} \mathrm{C}$, even $1,078 \mathrm{kWh}$ of power was consumed. Next day ( 9 October) almost $1,200 \mathrm{kWh}$ had to be used to heat the same amount of the binder up to $155^{\circ} \mathrm{C}$. To maintain the same temperature (not to allow it to cool) in a 65-tonne capacity bitumen tank, all maximum power of the base heating equipment, i.e. $288 \mathrm{kWh}$, in 24 hours was used. Theoretically, the maximum amount of heat transferred by heating equipment may be $1.392 \mathrm{kWh}$. The content of bitumen impacts on how much power will be required to maintain the required temperature. To maintain steady temperature, the base heating equipment uses ca $35-40 \%$ of power, and ca $60-65 \%$ of power is used to heat bitumen, e.g. delivered by a bitumen tanker (Fig. 3b).

The summary on the consumed power shows that the base heating equipment of the third tank under investigation was operating at the capacity of $57 \%$, and additional heating equipment worked at the capacity of more than $37 \%$.

Having investigated the factual electrical power consumption in one of AMPs operating in Lithuania, it was found out that ambient air temperature and wind speed have impact on the power consumed to heat 1 tonne of bitumen. Data on average daily air temperature and wind speed in October were used for investigation. Base (46 kW) and additional (12 kW) heating equipment in a $120 \mathrm{~m}^{3}$ capacity tank heated bitumen up to $160^{\circ} \mathrm{C}$ throughout the whole period under investigation. Quantity $q$ of the electrical power consumed to heat 1 tonne of bitumen was calculated by dividing the total amount of the consumed energy in 24 hours by the quantity of bitumen content in tonnes in that tank:

a)

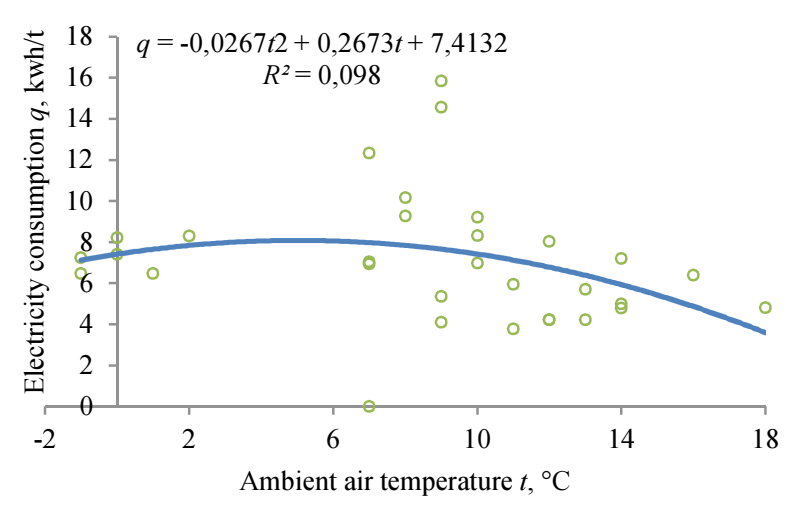

b)

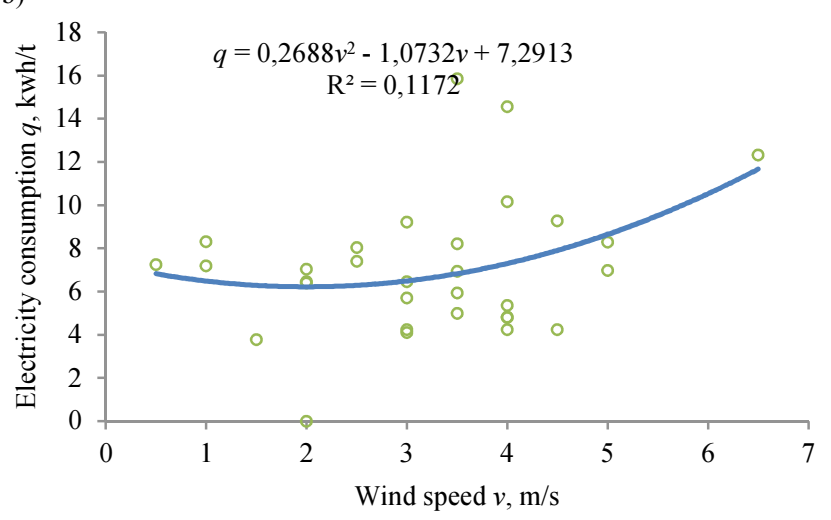

Fig. 5. Dependence of the quantity of electrical power consumed to heat 1 tonne of bitumen in a tank in 24 hours on: ambient air temperature (a); wind speed (b)

Having processed AMP computer data, which show the electrical power consumed each day of the month by the base and additional heating equipment, the bitumen content and heating modes in a tank, it was identified from the the 
determination coefficient that 10 per cent of the electrical power consumed in 24 hours was impacted by ambient air temperature and ca 12 per cent by wind speed (Fig. 5). It shows that other factors, such as initial bitumen temperature, bitumen and air ratio in a tank, insulation characteristics of the tank's wall impact most on the heat flow.

\section{Conclusions}

1. To maintain sustainable temperature of dried and heated mineral aggregates in AMP during a working day and to reduce the amount of natural gas used to heat them, the stockpiles of these materials should be sheltered. An AMP operator shall constantly monitor the temperature of hot fractions and when it goes up, change the drying-heating mode (intensity of burner's flame) of cold mineral aggregates' immediately. To save energy resources, to reduce air pollution and to protect bitumen from overheating, WMA mixtures may be produced with it instead of HMA mixtures. Recently, the use of WMA mixtures has been expanding in the world.

2. Power is used ineffectively in BBS equipment. Due to non-insulated BBS equipment, energy losses increase, it becomes more difficult to control and regulate the general temperature of bitumen content in BBS, congestion of viscous bitumen which impedes or stops altogether the flow of liquid bitumen in a pipeline occur. Unevenly insulated and at some points not insulated at all technological equipment may be the cause of bitumen overheating. An operator sets too high heating temperature not to allow bitumen to cool at the least insulated points, which speeds up the degradation of the binder.

3. The electrical power consumption to heat bitumen in a tank was $10 \%$ influenced by ambient air temperature and ca $12 \%$ by wind speed. Having analysed average power consumption, it turned out that bitumen content in a tank, job-mixformula temperature and physical properties of the tank's wall layers are the main factors impacting on power consumption. In the future, optimal heating modes of tanks shall be determined under Lithuanian climatic conditions taking into account different day and night electrical power prices.

\section{References}

[1] Jenks, Ch. W.; Jenks, C. F.; Harrigan, E. T.; Adcock, M.; Delaney, E. P.; Freer, H. 2011. A Manual for Design of Hot Mix Asphalt with Commentary, NCHRP Report 673. Washington, D.C.: Transportation Research Board. 273 p.

[2] Redelius, P. 2009. Asphaltenes in bitumen, what they are and what they are not, Road Materials and Pavement Design 10(sup1): 25-43 http://dx.doi.org/10.1080/14680629. 2009.9690234

[3] Liang, Y.; Feng, Z.; Yu, J. 2010. Effect of chemical compositions on temperature su-sceptibility of bitumens, Journal of Wuhan University of Technology-Mater. Sci. Ed. 25(4): 669-673. http://dx.doi.org/10.1007/s11595-040-0067-2

[4] Petersen, J. C.; Glaser, R. 2011. Asphalt oxidation mechanisms and the role of oxidation products on age hardening revisited, Road Materials and Pavement Design 12(4): 795-819. http://dx.doi.org/10.1080/14680629.2011.9713895

[5] Morian, N.; Hajj, E. Y.; Glover, C. J.; Sebaaly, P. E. 2011. Oxidative aging of asphalt binders in hot-mix asphalt mixtures, Transportation Research Record 2207: 107-116. http://dx.doi.org/10.3141/2207-14

[6] De Moraes, M. B.; Pereira, R. B., Simão, R. A.; Leite, L. F. M. 2010. High temperature AFM study of CAP 30/45 pen grade bitumen, Journal of Microscopy 239(1): 46-53. http://dx.doi.org/10.1111/j.1365-2818.2009.03354.x

[7] Herrington, Ph. R. 2012. Diffusion and reaction of oxygen in bitumen films, Fuel 94: 86-92. http://dx.doi.org/10.1016/j.fuel.2011.12.021

[8] Filippova, A. G.; Kirillova, L. G.; Okhotina, N. A.; Dvoyashkin, N. K.; Filippov, A. V.; Vol'fson, S. I.; Liakumovich, A. G.; Samuilov, Ya. D. 2000. Viscosity of polymer-bitumen binders, Colloid Journal 62(6): 755-758. http://dx.doi.org/10.1023/ A:1026639010912

[9] Dessouky, S.; Reyes Ch.; Ilias, M.; Contreras, D.; Papagiannakis, A. T. 2011. Effect of pre-heating duration and temperature conditioning on the rheological properties of bitu-men, Construction and Building Materials 25(6): 2785-2792. http://dx.doi.org/10.1016/ j.conbuildmat.2010.12.058

[10] Tran, N.; Taylor, A. J.; West, R. C.; Kvasnak, A.; Turner, P. 2010. Evaluation of predic-tive models for determination of binder critical high temperature from mixture proper-ties, in TRB 89th Annual Meeting Compendium of Papers DVD, Washington, D.C.: Trans-portation research board of the National academies.

[11] Huh, J. D.; Robertson, R. E. 1996. Modeling of oxidative aging behavior of asphalts from short-term, high-temperature data as a step toward prediction of pavement aging, Transportation Research Record 1535: 91-97. http://dx.doi.org/10.3141/1535-12

[12] Peinado, D.; de Vega, M.; García-Hernando, N.; Marugán-Cruz C. 2011. Energy and exergy analysis in an asphalt plant's rotary dryer, Applied Thermal Engineering 31(6-7): 1039-1049. http://dx.doi.org/10.1016/j.applthermaleng.2010.11.029

[13] Puello, J.; Afanasjeva, N.; Alvarez, M. 2013. Thermal properties and chemical composi-tion of bituminous materials exposed to accelerated ageing, Road Materials and Pave-ment Design 14(2): 278-288. http://dx.doi.org/10.1080/14680629.2013.785799

[14] Firoozifar, S. H.; Foroutan, S.; Foroutan, S. 2011. The effect of asphaltene on thermal properties of bitumen, Chemical Engineering Research and Design 89(10): 2044-2048. http://dx.doi.org/10.1016/j.cherd.2011.01.025

[15] Bolliet, C.; Juery, C.; Thiebaut, B. 2013. Impact of Oxidation Process on Polycyclic Aromatic Hydrocarbon (PAH) Content in Bitumen, Journal of Occupational and Environmental Hygiene 10(8): 435-445. http://dx.doi.org/10.1080/15459624.2013.801820

[16] Butt, A. A.; Mirzadeh, I.; Toller, S.; Birgisson, B. 2012. Life cycle assessment framework for asphalt pavements: methods to calculate and allocate energy of binder and additives, International Journal of Pavement Engineering. http://dx.doi.org/10.1080/10298436.2012.718348

[17] Deygout, F. 2011. Volatile emissions from hot bitumen storage tanks, Environmental Progress \& Sustainable Energy 30(1): 102-112. http://dx.doi.org/10.1002/ep.10444

[18] Mogawer, W. S.; Austerman, A. J.; Bonaquist, R. 2012. Determining the influence of plant type and production parameters on performance of plantproduced reclaimed asphalt pavement mixtures, Transportation Research Record, Construction 2268: 71-81. http://dx.doi.org/10.3141/2268-09

[19] Sivilevičius, H.; Šukevičius, Š. 2009. Manufacturing technologies and dynamics of hot $\square$ mix asphalt mixture production, Journal of Civil Engineering and Management 15(2): 169-179. http://dx.doi.org/10.3846/1392-3730.2009.15.169-179

[20] Brown, E. R.; Collins, R.; Brownfield, J. R. 1989. Investigation of segregation of asphalt mixtures in the state of Georgia, Transportation Research Record No. 1217: 1-8.

[21] Лупанов, А. П.; Гладышев, Н. В. 2013. Энергозатраты при производстве асфальто-бетонных смесей, Наука и техника в дорожной отрасли 2: $36-37$ 
[22] Ang, B. W.; Fwa, T. F.; Ng, T. T. 1993. Analysis of process energy use of asphalt-mixing plants, Energy 18(7): 769-777. http://dx.doi.org/10.1016/0360-5442(93)90035-C

[23] Chollar, B. H.; Zenewitz, J. A.; Boone, J. G.; Tran, K. T.; Andersen, D. T. 1989. Changes occurring in asphalts in drum dryer and batch (pug mill) mixing operations, Transportation Research Record 1228: 145-155.

[24] Anderson, R. M. 2011. The Asphalt Binder Handbook MS-26, First edition, Lexington, KY: Asphalt Institute. $242 \mathrm{p}$

[25] Bari, J.; Witczak, M. W. 1996. Development of a new revised version of the Witczak E* predictive model for hot mix asphalt mixtures (with discussion), Journal of the Associa-tion of Asphalt Paving Technologists 75: 381-423.

[26] Goh, S. W.; You, Z.; Williams, R. C.; Li, X. 2011. Preliminary dynamic modulus criteria of HMA for field rutting of asphalt pavements: Michigan'a experience, Journal of Transportation Engineering 137(1): 37-45. http://dx.doi.org/ 10.1061/(ASCE)TE.1943-5436.0000191

[27] Sörensen, A.; Wichert, B. 2009. Asphalt and Bitumen. Ullmann's Encyclopedia of In-dustrial Chemistry, Weinheim: Wiley-VCH Verlag GmbH \& Co. KGaA. 273-294. http://dx.doi.org/10.1002/14356007.a03_169.pub2

[28] Yero, S. A.; Hainin, M. R. 2012. Viscosity characteristics of modified bitumen, ARPN Journal of Science and Technology 2(5): 500-503.

[29] TRA ASFALTAS 08 - Automobilių kelių asfalto mišinių techninių reikalavimų aprašas. 2008. [TRA ASFALTAS 08 - The description of the technical requirements of roads as- phalt mixture's] (in Lithuanian).

[30] Bražiūnas, J.; Sivilevičius, H. 2010. The bitumen batching system's modernization and its effective analysis at the asphalt mixing plant, Transport 25(3): 325-335. ISSN 1648-4142. http://dx.doi.org/10.3846/transport.2010.40. (Thomson Reuters ISI Web of Science).

[31] Bražiūnas, J.; Sivilevičius, H. 2013. Dependences of SMA mixture and its bituminous binder properties on bitumen batching system, mixing time and temperature on asphalt on asphalt mixing plant, Journal of Civil Engineering and Management 19(6): 862-872. http://dx.doi.org/10.3846/13923730.2013.843587

[32] ASTM D2493 / D2493M. 2009. Road and Paving Materials; Vehicle-Pavement Systems. Standard Viscosity-Temperature Chart for Asphalts. http://dx.doi.org/10.1520/D2493_D2493M-09 